\title{
Facile synthesis of stereoregular carbon fiber precursor polymers by template assisted solid phase polymerization
}

\author{
G. Santhana Krishnan ${ }^{1 *}$, A. Burkanudeen ${ }^{2}$, N. Murali ${ }^{1}$, H. Phadnis ${ }^{3}$ \\ ${ }^{1}$ Materials Science Division, CSIR-National Aerospace Laboratories, 560017 Bangalore, India \\ ${ }^{2}$ Post Graduate and Research Department of Chemistry, Jamal Mohammed College (Bharathidasan University), \\ Tiruchirappalli, India \\ ${ }^{3}$ Malvern-Aimil Application Laboratory, Naimex House, 560045 Bangalore, India
}

Received 8 February 2012; accepted in revised form 1 April 2012

\begin{abstract}
Predominantly isotactic stereoregular polyacrylonitrile copolymers (PAC) were prepared by solid phase polymerization techniques using hexagonal crystalline metal salts as template compounds. Stereoregular distributions of the prepared polymer were studied using high resolution ${ }^{13} \mathrm{C}$ nuclear magnetic resonance spectroscopy $\left({ }^{13} \mathrm{C} \mathrm{NMR}\right) \mathrm{spectra}$. The extent of isotacticity was directly determined from the peak intensity of the methine carbon $(\mathrm{CH})$. The triad tacticity from the intensities of methine carbon peaks were examined by statistical methods. It was found that the PAC was predominantly isotactic in stereoregularity, and its sequence distribution obeys Bernoulli statistics. The optimum polymerization conditions ensuring isotactic content over 50\% were disclosed experimentally. The chemical composition of PAC was confirmed with ${ }^{1} \mathrm{H}$ NMR data. The obtained polyacrylonitrile copolymers were also characterized for molecular parameters such as viscosity average molecular weight $\left(M_{\mathrm{v}}\right)$, number average molecular weight $\left(M_{\mathrm{n}}\right)$, weight average molecular weight $\left(M_{\mathrm{w}}\right)$ and polydispersity index.
\end{abstract}

Keywords: polymer synthesis, polyacrylonitrile copolymer, NMR, stereoregularity, molecular weight distribution

\section{Introduction}

Carbon fibers generally have excellent mechanical properties such as high specific strength, specific modulus and are therefore widely used as strength modifiers for various reinforcing materials in aerospace applications, leisure goods, industrial materials and the like. Because of their superior mechanical properties, they have potential application for reducing automobile weight and are receiving increasing attention as an important advancement in solving the urgent problem of reducing carbon dioxide [1]. Acrylonitrile based copolymers (PAC) are an important class of precursors for high value carbon based materials, such as carbon fiber composites with high mechanical, thermal resistance and mesoporous carbon for use in photoelectronic devices [2-5]. The essential requirements that PAC precursors for high performance carbon materials must possess are high molecular weight and well controlled molecular architecture [6-7].

Commercially high molecular weight PAC is prepared by conventional radical polymerization much of them aqueous slurry process using various water soluble free radical initiators [8]. Various parameters such as comonomers type, temperature, initiator systems, polymerization media etc., influence the properties of the final polymer [9]. It is difficult to control polydispersity index (typically, $M_{\mathrm{w}} / M_{\mathrm{n}}<$ 3.0). Similarly, it is difficult to control the chain architecture and microstructure of the polymer, specifically the stereoregularity of the polymer main chain described by its tacticity. The carbon

\footnotetext{
${ }^{*}$ Corresponding author, e-mail: santhana@nal.res.in
}

(c) BME-PT 
fiber microstructure depends on the precursors and processing conditions. The stereoregularity as defined in terms of isotactic triad content of PAC often significantly affects the properties and functions of the polymers. Therefore, stereocontrol during polymerization is very important. More than three decade ago, Lewis acids were found to significantly influence the monomer reactivity during free-radical polymerization [10], and later, its stereochemistry [11]. However, the influence of Lewis acids on the stereochemistry during radical polymerization had not been reported. Isobe et al. [12] reported the efficient stereocontrol radical polymerization of acrylamides using Lewis acids as catalyst such as scandium trifluoromethanesulfonate and benzyl $\alpha$ methoxymethylacrylate. In general, stereospecific polymerization has been attained through an ionic or coordination process with metal based initiator as catalyst, which can provide a countercationic or anionic species at the growing end. Conventional radical polymerization as applied to all vinyl monomers lacks a counter ionic species in the process, thereby resulting in the stereoirregular structures in the obtained polymers. Most commonly employed method for preparing high molecular weight PAC with well controlled stereoregularity is anionic polymerization, however this method yields polymer with branched structures which affects the process efficiency during the solution spinning process and stability of the polymer solution. Therefore, a method for facile synthesis of stereo controlled PAC continues to be subject of study. The stereoregularity of polyacrylonitrile was first determined by Matsuzaki et al. [13] from proton NMR spectra of deuterated polymers and established that the radically obtained polymer has an atactic structure.

Kamide and coworkers [14, 15] have synthesized highly isotactic PAN by gamma-ray irradiation assisted solid state polymerization on acrylonitrileurea canal complex. Matsuzaki and coworkers [13, 16] and later Minagawa et al. [17] established that polyacrylonitrile obtained through X-ray or gammaray irradiation by solid phase polymerization of urea-canal complex has isotactic rich structure. Kamide et al. [18] have reported a polymer synthesis procedure for preparing high molecular weight, linear and high stereoregular polyacrylonitrile using anionic initiators including dialkylmagnesium. Considering the large scale requirements of $\mathrm{PAC}$ in the manufacture of carbon fiber precursor polymers, these processes seem to be extravagant. The synthesis of a carbon fiber polymer precursor with high linearity, molecular weight and isotactic stereoregularity include the solid phase polymerization at low temperature $\left(-75^{\circ} \mathrm{C}\right)$ using a urea/monomer clathrate complex reported by White [19]. However the unsaturated comonomers are absorbed on to crystalline materials, reducing the comonomer content in PAC. Therefore a robust synthesis procedure is a huge step toward development of a process for industrial scale production of high molecular weight PAC with isotacticity content more than $30 \mathrm{wt} \%$.

PAC with high isotactic stereoregularity is preferred over atactic and syndiotactic contents in the manufacture of high tensile grade carbon fibers. One of the critical stages in the carbon fiber production is thermal oxidative stabilization reaction which involves intramolecular cyclization of adjacent nitrile groups in the structural chain. PAC with high isotactic content, wherein the nitrile groups are in a meso configuration is advantageous from a positional point of view for cyclization of the adjacent nitrile groups as compared to the other stereo structures [12]. Moreover, the dimensions of the hexagonal plane layer which forms during the subsequent carbonization or graphitization is larger than one achieved using conventional PAC with an atactic structure and thereby the strength of the resulting carbon fibers is increased.

Controlled radical polymerization (CRP), which has undergone significant progress in the past decade, enables the facile synthesis of polymers with controlled molar mass, narrow distribution of molecular weights, well defined architecture and site specific functionalities [20-26]. Among these CRP methods, atom transfer radical polymerization is perhaps the most desirable mechanism in terms of controllability. However, it is difficult to scale-up these processes due to the complex synthesis procedures involved. Moreover the physical properties of polymer depend on the primary structure of the polymer chain; therefore the polymer synthesis is designed to control the primary structure such as molecular mass of polymer, molecular mass distribution, branch structure and terminal structure or stereo structure [27-30]. The main objective of this study was the synthesis of well defined, linear, high stereo 
regular PAC by applying a new polymerization technique.

In this research work, the PAC polymers such as poly(acrylonitrile-co-itaconic acid) and poly(acrylonitrile-co-acrylamide) were synthesized using template assisted solid phase polymerization technique and characterized for their molecular characteristics such as viscosity average molecular weight $\left(M_{\mathrm{v}}\right)$, weight average molecular weight $\left(M_{\mathrm{w}}\right)$, number average molecular weight $\left(M_{\mathrm{n}}\right)$, molecular weight distribution and stereo regularity in terms of isotactic triad content [mm wt $\%$ ]. This research has revealed that carbon fiber precursor polymer with high linearity, average molecular weight and isotacticity triad content greater than $50 \%$ could be successfully obtained through the solid phase polymerization assisted by template compounds.

\section{Experimental}

\subsection{Materials}

Synthesis grade acrylonitrile (AN) (110213), acrylamide (ACM) (79-06-1) and itaconic acid (ITA) (129204) [Sigma Aldrich Co. Ltd., Germany] were used in the polymer synthesis. Acrylonitrile was washed with sodium hydroxide solution of lower concentration $0.5 \mathrm{wt} \%$ and distilled at its boiling range just before polymerization to remove the inhibitor content. The hexagonal crystalline metal salts (anhydrous nickel chloride or magnesium chloride) (449172) [Sigma Aldrich Co. Ltd., Germany] was used as a template compound. Acrylamide and Itaconic acid were used as comonomers without further purification. Commercially available $\alpha, \alpha$ azoisobutryonitrile (AIBN) (78-67-1) [Sigma Aldrich Co. Ltd., Germany] was used as initiator after crystallization in methanol. Analytical grade dimethylsulphoxide (DMSO) (276855) [Sigma Aldrich Co. Ltd., Germany] was used for the measurements of polymer solution properties.

\subsection{Synthesis of isotactic rich stereoregular poly(acrylonitrile-co-itaconic acid), poly(acrylonitrile-co-acrylamide)}

The polymerization was carried out in a $500 \mathrm{~mL}$ three-necked round bottom flask, equipped with mechanical stirrer and a reflux condenser. The flask was bubbled with ultra pure $\mathrm{N}_{2}$ gas for $240 \mathrm{~min}$. to ensure an oxygen-free atmosphere. The template compounds used in this polymer synthesis is a hexagonal crystalline metal salt $\left(\mathrm{NiCl}_{2}\right.$ or $\left.\mathrm{MgCl}_{2}\right)$. The size of the template metal crystalline particles was in the range of $25-50 \mu \mathrm{m}$. The molar ratio of monomer and crystalline template compound was kept between 0.3 and 0.6 , to give an optimal amount of monomer to coordinate with template compound. Then, a mixture of acrylonitrile (AN), acrylamide/itaconic acid, and (2-2.5 wt\%) AIBN was added to the three-necked flask containing nickel chloride $(\mathrm{N})$ at room temperature, and allowed to thoroughly absorb to prepare an AN/N complex. In order to enhance the interconnectivity between template compound and monomer mixture, the mixture was kept under a constant stirring. A solid-phase polymerization was carried out by keeping the above AN/N complex in a hot air circulating drier for $6 \mathrm{~h}$ at $70^{\circ} \mathrm{C}$, and the final reaction mixture was poured into a pure methanol and precipitated. The white precipitate was filtered and washed several times with deionized water to remove the traces of metal salts and then dried under vacuum at $40^{\circ} \mathrm{C}$ for $24 \mathrm{~h}$.

\subsection{Characterization \\ FTIR}

FTIR spectra (National Aerospace Laboratories, Bangalore, India) were recorded on a Shimadzu IR Affinity 1 model (Shimadzu Corp. Tokyo, Japan), the resolution being $2 \mathrm{~cm}^{-1}$, using $\mathrm{KBr}$ pellets $(1 \mathrm{mg}$ samples as $400 \mathrm{mg} \mathrm{KBr}$ ). Typical conditions were as follows: wavenumber, $400-4000 \mathrm{~cm}^{-1}$, scanning, 32 counts; and purging gas, $\mathrm{N}_{2}$ (flow rate, $10 \mathrm{~L} / \mathrm{min}$ ). FTIR spectra were recorded using the $\mathrm{KBr}$ disk method.

\section{NMR}

The ${ }^{1} \mathrm{H}$ NMR and ${ }^{13} \mathrm{C}$ NMR (Bruker AMX-400, at Indian Institute of Science, Bangalore, India) spectra of the copolymers were recorded in DMSO using tetramethylsilane (TMS) as an internal standard [31]. Samples were concentrated in dimethyl sulphoxide about $5 \%(\mathrm{w} / \mathrm{w})$ for ${ }^{1} \mathrm{H} N \mathrm{NMR}$ and $5 \%(\mathrm{w} / \mathrm{w})$ for ${ }^{13} \mathrm{C}$ NMR and $2 \mathrm{D}$ NMR by using a $5 \mathrm{~mm}$ NMR tube at room temperature. ${ }^{1} \mathrm{H}$ NMR spectra were acquired using 21738 data points, spectral width $6 \mathrm{kHz}$, broadening $0.3 \mathrm{~Hz}$, pulse delay $1 \mathrm{~s}$, pulse width $90^{\circ}$, and 32 scans. ${ }^{13} \mathrm{C}$ NMR spectra were acquired using 24996 data points, spectral width $22 \mathrm{kHz}$, broadening $3 \mathrm{~Hz}$, pulse delay $2 \mathrm{~s}$, pulse width $90^{\circ}$, and 1024 scans. Nuclear 
overhauser effect (NOE) was suppressed by gating the decouple sequence. Heteronuclear multiple quantum coherence (HMQC) was performed by using the standard Bruker pulse sequence with a pulse program. The spectrum was obtained with 256 increments in the F1 dimension and 1024 data points in the F2 dimension, with 200 scans and relaxation delay $1.5 \mathrm{~s}$.

\section{Solution viscometry}

One hundred and fifty milligrams of a PAC sample dried by heat treatment at a temperature of $120^{\circ} \mathrm{C}$ for 2 hours and is dissolved at a temperature of $60^{\circ} \mathrm{C}$ into DMSO. The dropping time of the obtained solution between gauge marks is measured at an accuracy of $1 / 100$ seconds using Ubbelohde viscometer at a temperature of $25^{\circ} \mathrm{C}$. The measured dropping time is expressed as $t$ [sec]. Similarly the dropping time of DMSO is expressed as $t_{0}$. Intrinsic viscosity $(\eta)$ was obtained according to the following Equation (1) [32]:

$$
[\eta]=\left\{\left(1.44 \cdot \eta_{\mathrm{sp}}+1\right)\right\}^{1 / 2}-\frac{1}{0.36}
$$

where $\eta_{\mathrm{sp}}=t / t_{0}-1$. The viscosity average molecular weight of PAC was calculated by Equation (2) [33]:

$[\eta]=2.53 \cdot 10^{-4}\left[M_{\mathrm{w}}\right]^{0.72}$

\section{Membrane osmometry}

Osmotic pressure (П) of polymer solution was measured in the range of polymer concentration (C) from 0.3 to $0.9 \mathrm{~g} / \mathrm{dL}$ in DMSO at $60^{\circ} \mathrm{C}$ with Osmomat 090, Gonotec GmbH (Berlin, Germany) [34, 35]. Number average molecular weight $\left(M_{\mathrm{n}}\right)$ was obtained as $\Pi / \mathrm{C}$ extrapolated to $\mathrm{C}=0$ according to Equation (3):

$\lim _{\mathrm{C} \rightarrow 0} \Pi C^{-1}=R T\left(M_{\mathrm{n}}^{-1}\right)+A_{2} C$

where $R$ is gas constant.

Size exclusion chromatography -

Low angle laser light scattering (SEC-LALLS)

The SEC-LALLS instrument of Malvern Viscotek TDA 305 (Triple Detector Array, Malvern, United Kingdom) was used in this study [36]. The instru- ment was operated at $50^{\circ} \mathrm{C}$ with DMSO as solvent. A flow rate of $1 \mathrm{~mL} / \mathrm{min}$ and injection volume of $100 \mu \mathrm{L}$ was maintained. A concentration of $\sim 4.0 \mathrm{wt} \%$ was maintained in all samples. Low angle laser light scattering (LALLS) instrument was used as a detector at a fixed wavelength of $633 \mathrm{~nm}$. The molecular weight parameters were computed using SECLALLS data processing system. A set of polymethyl methacrylate (PMMA) standards of narrow molecular weight distribution (PolyCAL ${ }^{\mathrm{TM}}$, Viscotek, US) of molecular weight $2.0 \cdot 10^{4}-4.51 \cdot 10^{5}$ was used to calibrate the SEC-LALLS instrument. The carrier solvent was DMSO containing $0.05 \mathrm{~m}$ lithium bromide ( $\mathrm{LiBr}$ ) with a flow rate of $1 \mathrm{~mL} / \mathrm{min}$.

\section{Results and discussion}

This study primarily aimed to facilely synthesize a well defined, linear high molecular weight, and isotactic rich stereoregular PAC by thermal solid phase polymerization technique using hexagonal crystalline metal salts (Nickel chloride or Magnesium Chloride) with AIBN as initiator. The hexagonal crystalline metal salts adopt a layer structure on the macroscopic scale. Acrylonitrile monomers and unsaturated comonomers become enclosed between the crystalline metal compound layers with the polar groups orientated in the same direction to produce a regularly ordered arrangement. When particle size of the metallic compound is fine $(<5 \mu \mathrm{m})$, the PAC polymers were found to have lower molecular weight fractions. The general mechanism for the synthesis of PAC is represented in Figure 1. The Figure 2 shows the detailed representation of the various synthesis steps involved in the polymer synthesis.

The chemical composition of the respective copolymers as determined from ${ }^{1} \mathrm{H} N \mathrm{NMR}$ is given in Table 1. FTIR spectra of PAC are shown in Figure 3. The chemical structures of the copolymer are presented in Figure 4. The specific peak appearing at $2244 \mathrm{~cm}^{-1}$ in all spectra is associated with $-\mathrm{CN}$

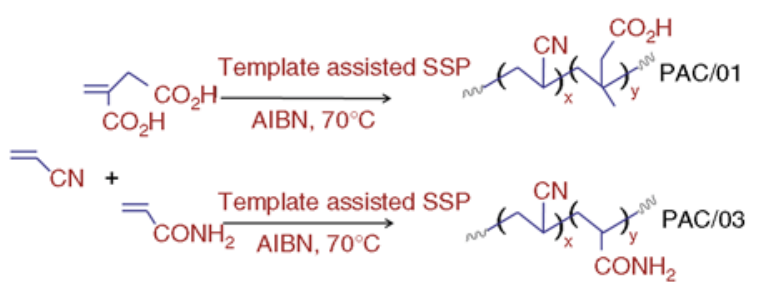

Figure 1. General mechanism for the synthesis of PAC 
Table 1. Chemical composition of PAC

\begin{tabular}{|c|c|c|c|}
\hline Sample code & \multicolumn{2}{|c|}{ Polymer composition [mol\%] } & AIBN [wt\%] \\
\hline $\mathrm{PAC} / 01$ & $\mathrm{AN}(98.5)$ & ITA(1.5) & 2.5 \\
\hline $\mathrm{PAC} / 02$ & $\mathrm{AN}(98.5)$ & ITA(1.5) & 2.0 \\
\hline $\mathrm{PAC} / 03$ & $\mathrm{AN}(98.5)$ & $\operatorname{ACM}(1.5)$ & 2.0 \\
\hline $\mathrm{PAC} / 04$ & $\mathrm{AN}(98.5)$ & $\operatorname{ACM}(1.5)$ & 2.5 \\
\hline
\end{tabular}

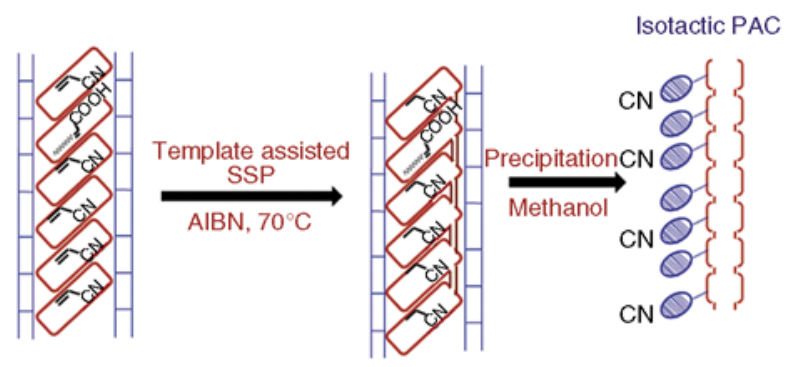

AN/metal template complex

Figure 2. Schematic representation of the solid state polymerization process

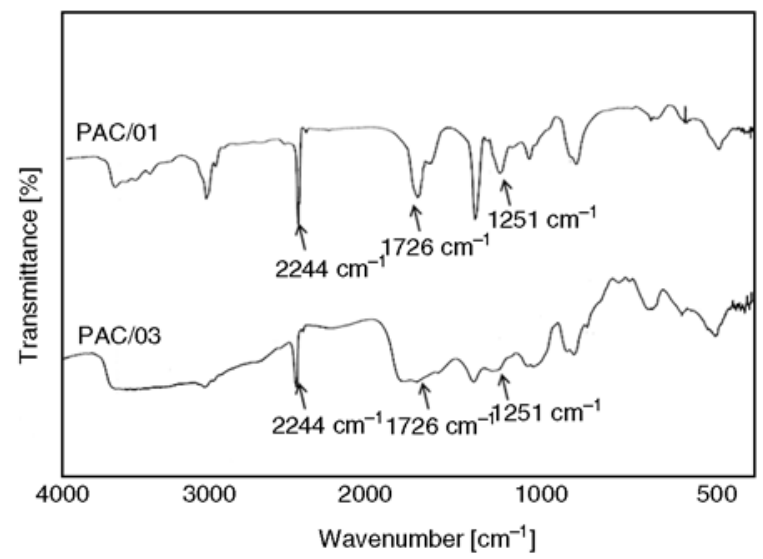

Figure 3. FTIR spectra of PAC/01 and PAC/03 copolymer sample

groups stretching vibration. The strong peak at $\sim 1726 \mathrm{~cm}^{-1}$ appearing in both spectrum of the copolymers is associated with carboxyl groups $(\mathrm{C}=\mathrm{O})$ stretching vibration. The absorption peak at $\sim 1251 \mathrm{~cm}^{-1}$ corresponds to $\mathrm{C}-\mathrm{O}$ or $\mathrm{C}-\mathrm{N}$ stretching vibration. These characteristics peaks in the spectra confirm the copolymer structures.

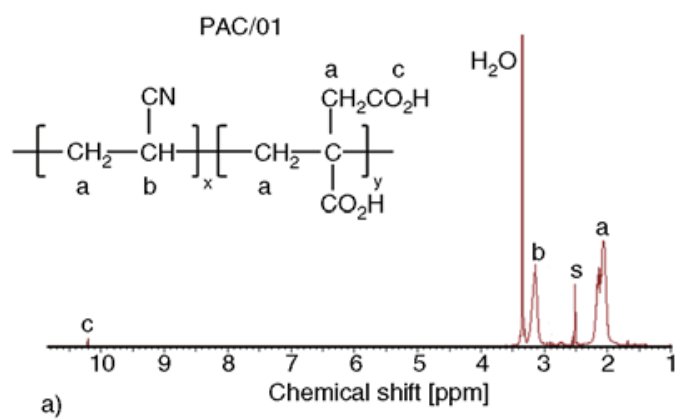

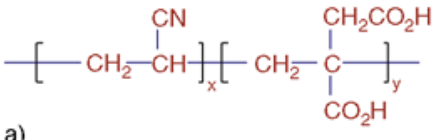

a)<smiles>CCCCC(C#N)CCC(C#N)C(N)=O</smiles>

b)

Figure 4. Chemical structures of PAC samples: (a) PAC/01 $\& \mathrm{PAC} / 02$, and (b) $\mathrm{PAC} / 03$ \& $\mathrm{PAC} / 04$

${ }^{1} \mathrm{H}$ NMR spectra of PAC/01 and PAC/03 corresponding to poly[acrylonitrile-co-itaconic acid], poly [acrylonitrile-co-acrylamide] are shown in Figure $5 \mathrm{a}$ and $5 \mathrm{~b}$. It can be seen that, the spectrum was complicated due to spin-split and coupling of methylene protons from both acrylonitrile and itaconic acid monomers in Figure 5a. The signals of methylene protons $\left(-\mathrm{CH}_{2}\right)$ from acrylonitrile and itaconic acid monomer units appeared at 2.1-2.2, and 2.3$2.4 \mathrm{ppm}$ respectively. The signals corresponding to characteristic methine proton $(-\mathrm{CH})$ and $-\mathrm{COOH}$ proton from itaconic acid were observed at 3.25 and $10.2 \mathrm{ppm}$ respectively. The characteristic amide proton $\left(-\mathrm{CONH}_{2}\right)$ from acrylamide corresponding to signal at $7.9 \mathrm{ppm}$. Compositions of the PAC/01$\mathrm{PAC} / 04$ were determined by measuring the integrated areas of the resolved peaks corresponding to functional groups of respective monomers in ${ }^{1} \mathrm{H}$ NMR spectra.

The plot of reduced viscosity as a function of concentration of all samples in DMSO is shown in Figure 6 . The viscosity average molecular weight of the PAC polymers determined using Equation (2) is given in Table 2. The osmotic pressure values of samples such as PAC/01-PAC/04 are measured in DMSO at $60^{\circ} \mathrm{C}$. The plot of reduced osmotic pressure, $\Pi / \mathrm{C}$, against concentration, $\mathrm{C}$, of all the polymer solutions is shown in the Figure 7. In all cases

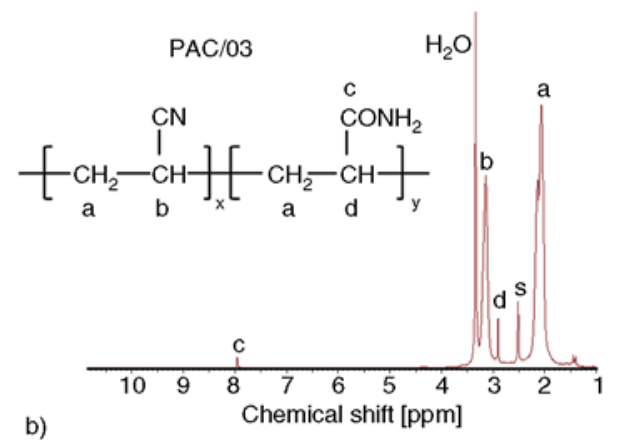

b)

Figure 5. ${ }^{1} \mathrm{H}$ NMR spectra of (a) PAC/01 and (b) PAC/03 in DMSO-d $\mathrm{d}_{6}$ at $25^{\circ} \mathrm{C}$ 
Table 2. Viscometry, osmometry, and SEC-LALLS results for different samples

\begin{tabular}{|c|c|c|c|c|c|c|c|c|c|}
\hline $\begin{array}{c}\text { Sample } \\
\text { code }\end{array}$ & $\begin{array}{c}{[\eta]^{\mathrm{a}}} \\
{[\mathrm{g} / \mathrm{dL}]}\end{array}$ & $\begin{array}{c}\mathrm{M}_{\mathrm{v}}{ }^{\mathrm{a}} \cdot 10^{-5} \\
{[\mathrm{~g} / \mathrm{mol}]}\end{array}$ & $\begin{array}{c}\mathbf{M}_{\mathrm{n}}^{\mathrm{b}} \cdot 10^{-4} \\
{[\mathrm{~g} / \mathrm{mol}]}\end{array}$ & $\begin{array}{c}M_{\mathrm{n}}^{\mathrm{c}} \cdot 10^{-4} \\
{[\mathrm{~g} / \mathrm{mol}]}\end{array}$ & $\begin{array}{c}M_{w}{ }^{c} \cdot 10^{-5} \\
{[g / m o l]}\end{array}$ & $\begin{array}{c}\mathrm{M}_{\mathrm{z}}^{\mathrm{c}} \cdot \mathbf{1 0} 0^{-5} \\
{[\mathrm{~g} / \mathrm{mol}]}\end{array}$ & $\mathbf{M}_{\mathbf{v}}{ }^{\mathrm{a}} / \mathbf{M}_{\mathbf{n}}{ }^{\mathrm{b}}$ & $\mathbf{M}_{w} / \mathbf{M}_{\mathbf{n}}{ }^{\mathbf{c}}$ & $\mathbf{M}_{\mathbf{z}} / \mathbf{M}_{\mathbf{w}}{ }^{\mathbf{c}}$ \\
\hline $\mathrm{PAC} / 01$ & 2.24 & 3.06 & 14.3 & 11.8 & 2.57 & 4.31 & 2.13 & 2.168 & 1.68 \\
\hline $\mathrm{PAC} / 02$ & 1.43 & 1.64 & 7.8 & 4.7 & 1.17 & 2.25 & 2.10 & 2.503 & 1.92 \\
\hline $\mathrm{PAC} / 03$ & 1.70 & 3.26 & 10.2 & 7.21 & 1.73 & 3.18 & 3.20 & 2.411 & 1.84 \\
\hline $\mathrm{PAC} / 04$ & 1.90 & 2.44 & 11.2 & 7.49 & 1.60 & 3.17 & 3.03 & 2.147 & 1.99 \\
\hline
\end{tabular}

${ }^{\mathrm{a}}$ By viscometry

${ }^{\mathrm{b}}$ By membrane osmometry

'By SEC-LALLS

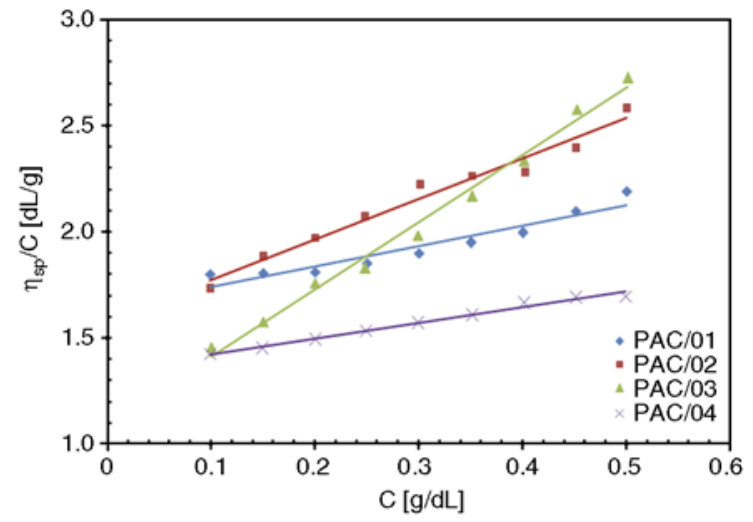

Figure 6. The plots of reduced viscosity as a function of concentration for PAC in DMSO at $30^{\circ} \mathrm{C}$

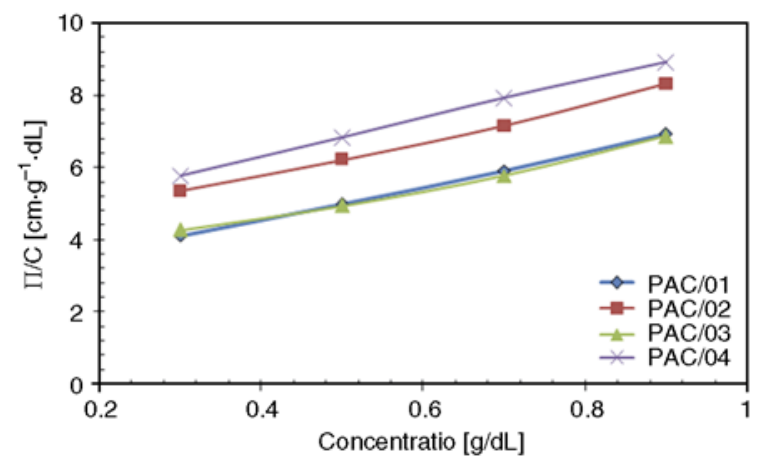

Figure 7. The plots of reduced osmotic pressure (П/C) against concentration $\mathrm{C}$ for PAC in DMSO at $60^{\circ} \mathrm{C}$

linear relations are obtained when extrapolated to $\mathrm{C}=0$ with a linear regression coefficient of 0.9945 . From the extrapolation of the Van't Hoff plots, the value of number average molecular weight $\left(M_{\mathrm{n}}\right)$ is determined. A set of four monodispersed polymethyl methacrylate (PMMA) standards corresponding to molecular weights from $2.0 \cdot 10^{4}-4.51 \cdot 10^{5}$ is used to calibrate SEC-LALLS instrument. A calibration data of retention volume-detector response corresponding to four different monodisperse (PMMA) standards is given in Table 3.

The molecular weight $\left(M_{\mathrm{n}}, M_{\mathrm{w}}, M_{\mathrm{z}}\right)$ and the molecular weight distribution $\left(M_{\mathrm{w}} / M_{\mathrm{n}}\right)$ were determined using SEC-LALLS. The values of $M_{\mathrm{n}}, M_{\mathrm{w}}, M_{\mathrm{z}}$ and
Table 3. Average molecular weight of PMMA calibration standards

\begin{tabular}{|c|c|}
\hline Sample No & Molecular weight [g/mol] \\
\hline PMMA1 & 451000 \\
\hline PMMA2 & 139000 \\
\hline PMMA3 & 52600 \\
\hline PMMA4 & 20800 \\
\hline
\end{tabular}

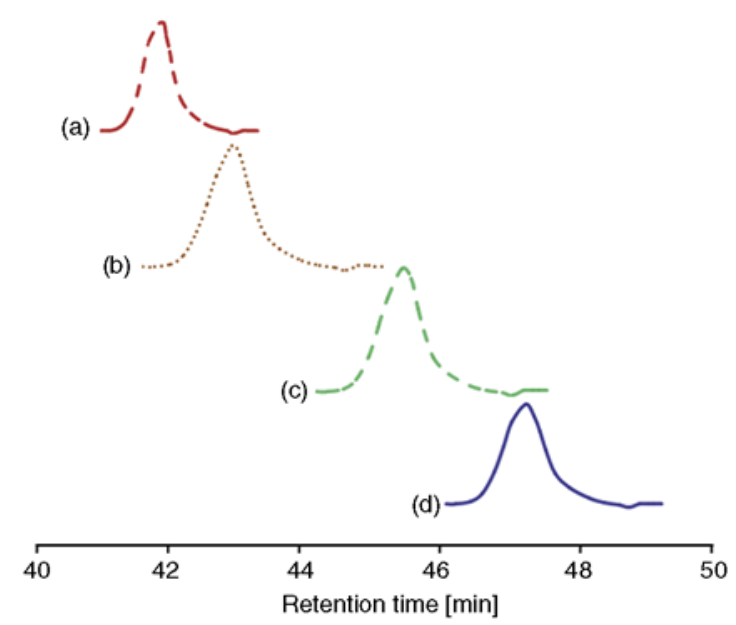

Figure 8. SEC-LALLS elution curves for PAC, a) PAC/01, b) $\mathrm{PAC} / 04$, c) $\mathrm{PAC} / 03$, d) $\mathrm{PAC} / 04$

MWD are calculated for PAC/01-PAC/04 using SEC-LALLS data processing system which is given in Table 2. The ratio of $M_{\mathrm{w}} / M_{\mathrm{n}}$ varies between 2.1 to 2.5 and also the ratio of $M_{\mathrm{z}} / M_{\mathrm{w}}$ varies between 1.6 to 2.0. Figure 8a-d shows SEC-LALLS elution curves for PAC/01-PAC/04. The values of $M_{\mathrm{v}}, M_{\mathrm{n}}$ (osm), $M_{\mathrm{n} \text { (SEC-LALLS) }}, M_{\mathrm{w}}$, and $M_{\mathrm{z}}$ are $1.61-3.26 \cdot 10^{4}, 7.8-$ $14.3 \cdot 10^{4}, 4.7-11.8 \cdot 10^{4}, 1.1-2.57 \cdot 10^{5}$, and $2.25-$ $4.31 \cdot 10^{5} \mathrm{~g} / \mathrm{mol}$ respectively. It has been authors' experience that $M_{\mathrm{n}}$ values determined by SEC-LALLS are rarely in agreement with $\mathrm{Mn}$ values from the membrane osmometer, SEC-LALLS values generally being lower than $M_{\mathrm{n}}$ values determined from the osmometer.

The stereoregularity of PAC/01-PAC/04 are also estimated in terms of triad tacticity content using ${ }^{13} \mathrm{C}$ NMR spectra. Basically, due to higher resolu- 


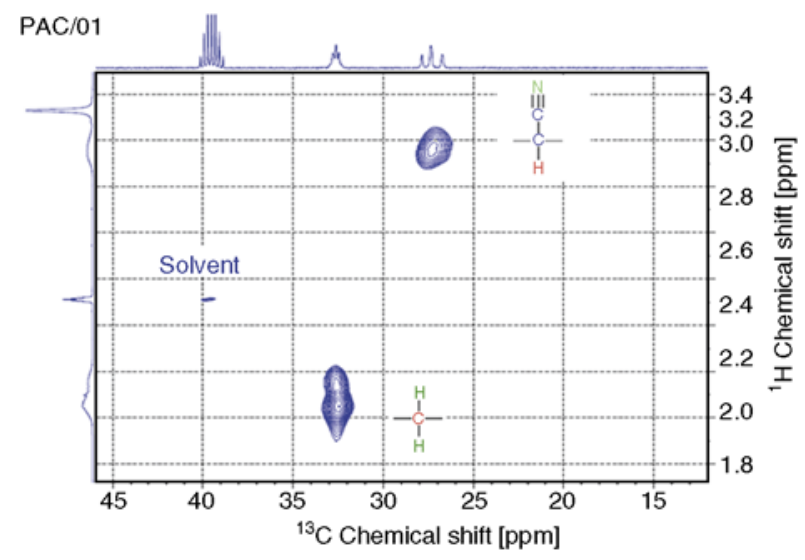

Figure 9. 2D-NMR - COSY-HMQC Techniques: ${ }^{13} \mathrm{C}-{ }^{1} \mathrm{H}$ shift correlation NMR spectra

tion and more extensive sweep width, this technique is used in most studies. The bonding network between methine carbon and methine hydrogen is established using 2D-NMR - COSY-HMQC technique which is shown in Figure 9. HMQC spectrum can also be used in the assignment of the proton spectrum by dispersing the proton resonances along the ${ }^{13} \mathrm{C}$ dimension and reducing its multiplet overlaps. ${ }^{13} \mathrm{C}$ NMR spectra with wide magnetization field caused higher splitting which was observed for all carbons.

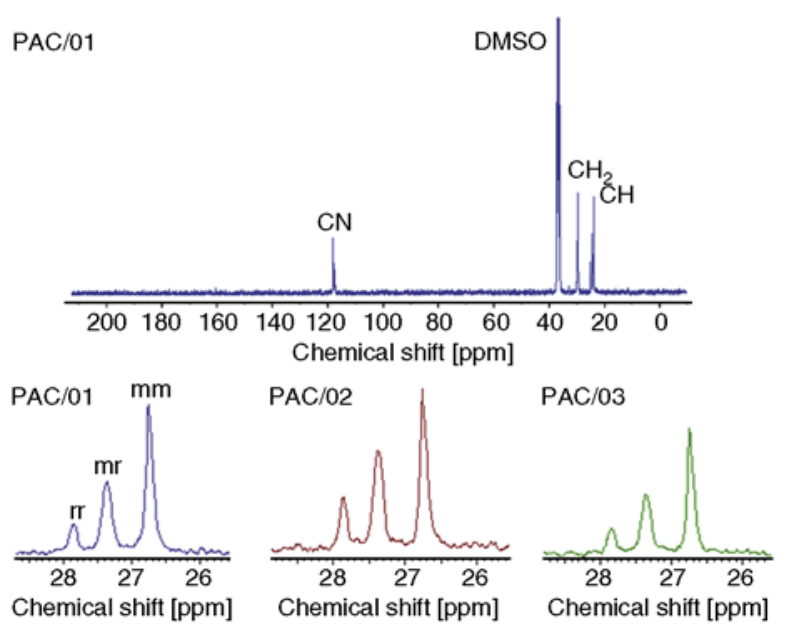

Figure 10. ${ }^{13} \mathrm{C}$ NMR spectra of isotactic PAC. Only methine carbon region is expanded (bottom).
Figure 10 shows the typical ${ }^{13} \mathrm{C}$ NMR spectra of stereoregular isotactic PAC in which three types of carbon are observed: methine $(\mathrm{CH})$, methylene $\left(\mathrm{CH}_{2}\right)$, and cyano-carbon $(\mathrm{CN})$. Assignments of methine carbon peaks were adopted as Minagawa et al. [37] which used NMR-400 MHz spectrometer with similar splitting for carbons. The triad tacticities of the polymers prepared were analyzed using methine carbon $(\mathrm{CH})$ signals in the region 26.7-27.9 ppm. They consisted of three main peaks, corresponding to three possible steric triad configurations. The peaks at 26.75, 27.3, and $27.86 \mathrm{ppm}$ correspond to isotactic $(\mathrm{mm})$, atactic $(\mathrm{mr})$, and syndyotactic (rr) respectively. The relative intensities of the peaks corresponding to methine carbon were used for determining the triad tacticity of PAC. The extent of isotacticity $(\mathrm{mm})$ of these samples was found to be in the range of 47.6-51.4\% (Table 4). The Bernoulli statistics is held satisfactorily for the PAC samples as listed in Table 4.

Two of the essential requirements that, polymer precursors for high performance carbon fiber materials must possess are high molecular weight and well controlled architecture $[6,7]$. The molecular and structural characteristics of carbon fiber precursor polymers synthesized through conventional polymerization processes such as aqueous slurry, and solution techniques are presented in Table 5. Typically the molecular characteristics of PAC are $M_{\mathrm{n}}\left(4.25 \cdot 10^{4}\right), M_{\mathrm{v}}\left(2.09 \cdot 10^{5}\right), M_{\mathrm{W}}\left(1.82 \cdot 10^{5}\right)$ (suspension process) and $M_{\mathrm{n}}\left(4.28 \cdot 10^{4}\right), M_{\mathrm{v}}\left(1.61 \cdot 10^{5}\right)$, $M_{\mathrm{w}}\left(1.43 \cdot 10^{5}\right)$ (solution process). In the present solid phase polymerization technique, the molecular weight increased with conversion and molecular weight distribution around 2.1-2.5 throughout the polymer synthesis. There was also a strong dependence of the initiator concentration on the molecular weight of the polymer. Then, the molecular weights increased in a linear fashion with increasing conversion and that the absolute molecular weights $\left(M_{\mathrm{n}}\right.$ (osmometry) $\left.\left(7.8-14.3 \cdot 10^{4}\right)\right)$ were close to the

Table 4. Characterization of stereoregular PAC samples

\begin{tabular}{|c|c|c|c|c|c|c|c|}
\hline \multirow{2}{*}{ Sample code } & \multicolumn{3}{|c|}{ Chemical shift [ppm] } & \multicolumn{4}{c|}{ Triad tacticity [\%] } \\
\cline { 2 - 8 } & $\mathbf{m m}$ & $\mathbf{m r}$ & $\mathbf{r r}$ & $\mathbf{I}^{\mathbf{a}}$ & $\mathbf{A}^{\mathbf{b}}$ & $\mathbf{S}^{\mathbf{c}}$ & 4IS/A $^{\mathbf{2}}$ \\
\hline PAC/01 & 26.77 & 27.39 & 27.86 & 47.8 & 37.4 & 14.8 & 2.023 \\
\hline PAC/02 & 26.76 & 27.39 & 27.85 & 47.6 & 36.9 & 15.5 & 2.167 \\
\hline PAC/03 & 26.76 & 27.36 & 27.86 & 51.4 & 33.9 & 14.7 & 2.629 \\
\hline PAC/04 & 26.76 & 27.37 & 27.84 & 50.1 & 35.6 & 14.3 & 2.261 \\
\hline
\end{tabular}

Isotactic

${ }^{\mathrm{b}}$ Atactic

'Syndiotactic 
Table 5. Molecular characteristics of PAC through different polymerization techniques

\begin{tabular}{|c|c|c|c|c|c|c|c|c|c|c|}
\hline \multirow{2}{*}{ Entry } & \multirow{2}{*}{ Polymer } & \multirow{2}{*}{ Process } & \multirow{2}{*}{ Solvent } & \multicolumn{4}{|c|}{ Molecular parameters } & \multicolumn{3}{|c|}{$\begin{array}{c}\text { Structural parameters } \\
\text { Triad tacticity [\%] }\end{array}$} \\
\hline & & & & $\begin{array}{c}\mathrm{M}_{\mathrm{v}} \cdot 10^{-5} \\
{[\mathrm{~g} / \mathrm{mol}}\end{array}$ & $\begin{array}{c}\mathrm{Mn} \cdot 10^{-4} \\
{[\mathrm{~g} / \mathrm{mol}]}\end{array}$ & $\begin{array}{c}\text { Mw } \cdot 10^{-5} \\
{[\mathrm{~g} / \mathrm{mol}]}\end{array}$ & $\mathbf{M}_{\mathbf{w}} / \mathbf{M}_{\mathbf{n}}$ & I & A & $\mathbf{S}$ \\
\hline 1 & $\begin{array}{l}\text { AN/ITA } \\
\text { copolymer } \\
98.5 / 1.5 ; \mathrm{wt} / \mathrm{wt} \\
\text { AIBN, } 50^{\circ} \mathrm{C}\end{array}$ & $\begin{array}{l}\text { Aqueous slurry } \\
\text { polymerization }\end{array}$ & $\mathrm{DMSO} / \mathrm{H}_{2} \mathrm{O}$ & 2.09 & 4.25 & 1.82 & 4.28 & 28.1 & 47 & 24.9 \\
\hline 2 & $\begin{array}{l}\text { AN/ITA } \\
\text { copolymer } \\
98.5 / 1.5 ; \mathrm{wt} / \mathrm{wt} \\
\text { AIBN, } 55^{\circ} \mathrm{C}\end{array}$ & $\begin{array}{l}\text { Solution } \\
\text { polymerization }\end{array}$ & DMSO & 1.61 & 4.28 & 1.43 & 3.34 & 26.4 & 48.5 & 25.1 \\
\hline 3 & $\begin{array}{l}\text { AN/ITA } \\
\text { copolymer } \\
98.5 / 1.5 ; \mathrm{wt} / \mathrm{wt} \\
\text { AIBN, } 70^{\circ} \mathrm{C}\end{array}$ & $\begin{array}{l}\text { Solid phase } \\
\text { polymerization }\end{array}$ & $\begin{array}{l}\text { No solvent } \\
\text { used }\end{array}$ & 1.64 & 4.70 & 1.17 & 2.503 & 50.1 & 35.6 & 14.3 \\
\hline
\end{tabular}

theoretical values determined by the ratio of the initial monomer and initiator concentration (i.e., $\left.M_{\mathrm{n} \text {,theo }}=53[\mathrm{AN}]_{0} /[\mathrm{AIBN}]_{0}\right)$. This means that the initiator efficiency of the polymerization was close to unity. The molecular weight characteristics of PAC obtained through solid phase polymerization are $M_{\mathrm{n}}\left(4.7 \cdot 10^{4}\right), M_{\mathrm{v}}\left(1.64 \cdot 10^{5}\right), M_{\mathrm{W}}\left(1.17 \cdot 10^{5}\right)$. This compares well with the other conventional polymerization processes.

\section{Conclusions}

Isotactic rich stereoregular PAC was synthesized by solid phase polymerization using hexagonal crystalline metal salts (Nickel chloride or Magnesium chloride) with AIBN as initiator. The bonding network between methine carbon and methine hydrogen is established using 2D-NMR - COSY-HMQC technique. ${ }^{1} \mathrm{H}$ NMR via $\mathrm{HMQC}$ triad sequence was also performed for methine protons. Assignment of stereosequences was performed on methine carbon at triad sequences level using ${ }^{13} \mathrm{C}$ spectroscopy. Bernoullian statistics is fitted well by the experimental results. The molecular weight distributions and various average molecular weights of PAC were estimated. Structure-property relationship, such as the intrinsic viscosity $(\eta)$ versus the number average molecular weight $\left(M_{\mathrm{n}}\right)$ found in DMSO is $\eta=2.53 \cdot 10^{-4} \cdot M_{\mathrm{n}}^{0.72}$. The molecular weight distributions of these polymers as determined from $M_{\mathrm{v}} / M_{\mathrm{n}}$ and $M_{\mathrm{w}} / M_{\mathrm{n}}$ were 2.1 to 3.2 and 2.1 to 2.5 respectively. It is concluded that PAC with isotactic content over $50 \%$ can be prepared successfully by solid phase polymerization.

\section{Acknowledgements}

Financial support by Council of Scientific and Industrial Research (CSIR), New Delhi under Supra Institutional Project (SIP-IFCAP-04) is gratefully acknowledged. We thank The Director, CSIR-National Aerospace Laboratories, Bangalore for his support and permission to publish this work. The authors also grateful to the management and principal of Jamal Mohammed College, Bharathidasan University, Tiruchirpalli, India for their encouragement and help.

\section{References}

[1] Frohs W., Jaeger H.: Carbon fiber and composite material. Tanso, 249, 174-178 (2011).

DOI: $10.7209 / \operatorname{tanso.2011.174}$

[2] Kroschwitz J. I.: Encyclopedia of polymer science and technology. Wiley, Hoboken (2003).

[3] Kowalewski T., Tsarevsky N. V., Matyjaszewski K.: Nanostructured carbon arrays from block copolymers of polyacrylonitrile. Journal of American Chemical Society, 124, 10632-10633 (2002). DOI: $10.1021 / \mathrm{ja} 0178970$

[4] Kruk M., Dufour B., Celer E. B., Kowalewski T., Jaroniec M., Matyjaszewski K.: Synthesis of mesoporous carbons using ordered and disordered mesoporous silica templates and polyacrylonitrile as carbon precursor. Journal of Physical Chemistry B, 109, 9216-9225 (2005).

DOI: $10.1021 / j p 045594 x$

[5] Long J. W., Dunn B., Rolison D. R., White H. S.: Three-dimensional battery architectures. Chemical Reviews, 104, 4463-4492 (2004). DOI: $10.1021 / \mathrm{cr} 0207401$

[6] Hou C., Qu R., Liu J., Ying L., Wang C.: High-molecular-weight polyacrylonitrile by atom transfer radical polymerization. Journal of Applied Polymer Science, 100, 3372-3376 (2006).

DOI: $10.1002 / a p p .23727$ 
[7] Pitto V., Voit B. I., Loontjens T. J. A., van Benthem R. A. T. M.: New star-branched poly(acrylonitrile) architectures: ATRP synthesis and solution properties. Macromolecular Chemistry and Physics, 205, 23462355 (2004).

DOI: $10.1002 /$ macp. 200400319

[8] Morgan P.: Carbon fiber and their composites. CRC Press, Boca Raton (2005).

[9] Kamide K., Dobashi T.: Physical chemistry of polymer solutions. Theoretical background. Elsevier, Amsterdam (2000).

[10] Wu G. Y., Qi Y. C., Lu G. J., Wei Y. K.: Alternating copolymerization of acrylate and isobutylene. Polymer Bulletin, 22, 393-400 (1989).

DOI: $10.1007 / \mathrm{BF} 00263078$

[11] Gotoh Y., Yamashita M., Nakamura M., Toshima N., Hirai H.: Stereoregulation in the alternating copolymerization giving highly coheterotactic poly(methyl methacrylate-alt-styrene). Direct determination of coisotactic parameters. Chemistry Letters, 21, 53-56 (1991). DOI: $10.1246 / \mathrm{cl} .1991 .53$

[12] Isobe Y., Fujioka D., Habaue S., Okamoto Y.: Efficient Lewis acid-catalyzed stereocontrolled radical polymerization of acrylamides. Journal of American Chemical Society, 123, 7180-7181 (2001).

DOI: $10.1021 / \mathrm{ja} 0158881$

[13] Matsuzaki K., Uryu T., Okada M., Shiroki H.: The stereoregularity of polyacrylonitrile and its dependence on polymerization temperature. Journal of Polymer Science, 6, 1475-1487 (1968).

DOI: $10.1002 /$ pol.1968.150060606

[14] Kamide K., Yamazaki H., Miyazaki Y.: Effects of stereoregularity on molecular parameters of polyacrylonitrile polymerized by gamma-ray irradiation. Polymer Journal, 18, 819-836 (1986).

DOI: $10.1295 /$ polymj.18.819

[15] Yamazaki H., Miyazaki Y., Kamide K.: Stereospecific polymerization of acrylonitrile using acrylonitrile-urea canal complex initiated by $\gamma$-ray irradiation: Roles of radical chain transfer reagents. Polymer Journal, 23, 765-779 (1991). DOI: $10.1295 /$ polymj.23.765

[16] Matsuzaki K., Okada M., Uryu T.: Triad tacticity of polyacrylonitrile. Journal of Polymer Science Part A1: Polymer Chemistry, 9, 1701-1714 (1971). DOI: 10.1002/pol.1971.150090619

[17] Minagawa K., Ute K., Kitayama T., Hatada K.: Determination of stereoregularity of $\gamma$-irradiation canal polymerized polyacrylonitrile by $1 \mathrm{H} 2 \mathrm{D}$ J-resolved NMR spectroscopy. Macromolecules, 27, 3669-3671 (1994). DOI: $10.1021 / \mathrm{ma} 00091 \mathrm{a} 032$

[18] Kamide K., Ono H., Hisatani K.: Stereospecificity in the polymerization of acrylonitrile using anionic initiators including dialkylmagnesium. Polymer Journal, 24, 917-930 (1992).

DOI: $10.1295 /$ polymj.24.917
[19] White D. M.: Stereospecific polymerization in urea canal complexes. Journal of American Chemical Society, 82, 5678-5685 (1960).

DOI: $10.1021 / \mathrm{ja} 01506 \mathrm{a} 031$

[20] Matyjaszewski K., Xia J.: Atom transfer radical polymerization. Chemical Reviews, 101, 2921-2990 (2001). DOI: $10.1021 / \mathrm{cr} 940534 \mathrm{~g}$

[21] Venkatesh R., Yajjou L., Koning C. E., Klumperman B.: Novel brush copolymers via controlled radical polymerization. Macromolecular Chemistry and Physics, 205, 2161-2168 (2004).

DOI: $10.1002 / \mathrm{macp} .200400252$

[22] Feng W., Brash J., Zhu S.: Atom-transfer radical grafting polymerization of 2-methacryloyloxyethyl phosphorylcholine from silicon wafer surfaces. Journal of Polymer Science Part A: Polymer Chemistry, 42, 2931-2942 (2004).

DOI: $10.1002 /$ pola.20095

[23] Hadjichristidis N., Latrou H., Pitsikalis M., Mays J.: Macromolecular architectures by living and controlled/ living polymerizations. Progress in Polymer Science, 31, 1068-1132 (2006).

DOI: $10.1016 / \mathrm{j}$. progpolymsci.2006.07.002

[24] Matyjaszewski K., Müller A. H. E.: 50 years of living polymerization. Progress in Polymer Science, 31, 1039-1040 (2006).

DOI: $10.1016 /$ j.progpolymsci.2006.09.002

[25] Braunecker W. A., Matyjaszewski K.: Recent mechanistic developments in atom transfer radical polymerization. Journal of Molecular Catalysis A: Chemical, 254, 155-164 (2006).

DOI: 10.1016/j.molcata.2006.01.076

[26] Braunecker W. A., Matyjaszewski K.: Controlled/living radical polymerization: Features, developments, and perspectives. Progress in Polymer Science, 32, 93146 (2007).

DOI: $10.1016 /$ j.progpolymsci.2006.11.002

[27] Cossens V., Pintauer T., Matyjaszewski K.: Functional polymers by atom transfer radical polymerization. Progress in Polymer Science, 26, 337-377 (2001). DOI: 10.1016/S0079-6700(01)00003-X

[28] Pyun J., Matyjaszewski K.: Synthesis of nanocomposite organic/inorganic hybrid materials using controlled/ 'living' radical polymerization. Chemistry of Materials, 13, 3436-3448 (2001). DOI: $10.1021 / \mathrm{cm} 011065 \mathrm{j}$

[29] Davis K., Matyjaszewski K.: Advances in polymer science. Springer, Berlin (2002).

[30] Pyun J., Kowalewski T., Matyjaszewski K.: Synthesis of polymer brushes using atom transfer radical polymerization. Macromolecular Rapid Communications, 24, 1043-1059 (2003). DOI: $\underline{10.1002 / \mathrm{marc} .200300078}$ 
[31] Ravi P., Divakar S.: $\beta$-cyclodextrin regulated stereoregularity and molecular weight in inclusion polymerization of acrylonitrile. Journal of Macromolecular Science Part A: Pure and Applied Chemistry, 36, 1935-1948 (1999).

DOI: $10.1081 / \mathrm{MA}-100101635$

[32] Tomoko I., Yuhei M.: Method for producing polyacrylonitrile based fiber and method for producing carbon fiber. Japanese Patent JP2011042893, Japan (2011).

[33] Sho T., Koichi S.: Precursor for carbon fiber, method for producing the same. Japanese Patent JP2001288613A, Japan (2001).

[34] Kany H-P., Hasse H., Maurer G.: Thermodynamic properties of aqueous poly(vinylpyrrolidone) solutions from laser-light-scattering, membrane osmometry, and isopiestic measurements. Journal of Chemical Engineering Data, 48, 689-698 (2003).

DOI: $10.1021 / \mathrm{je} 020203 \mathrm{y}$
[35] Ren L., Hardy C. G., Tang S., Doxie D. B., Hamidi N., Tang C.: Preparation of side-chain 18-e cobaltoceniumcontaining acrylate monomers and polymers. Macromolecules, 43, 9304-9310 (2010).

DOI: $10.1021 / \mathrm{ma101935a}$

[36] Imaizumi M., Okino Y., Yoshikawa K., Koyama K.: Relationship between intrinsic viscosity and molecular weight (MW) of PBS and PBSA determined by SECLALLS and SEC-viscometry (in Japanese). SeikeiKakou, 15, 419-423 (2003).

DOI: $10.4325 /$ seikeikakou.15.419

[37] Minagawa M., Taira T., Yabuta Y., Nozaki K., Yoshii F.: An anomalous tacticity-crystallinity relationship: A WAXD study of stereoregular isotactic (83-25) poly (acrylonitrile) powder prepared by urea clathrate polymerization. Macromolecules, 34, 3679-3683 (2001).

DOI: $10.1021 / \mathrm{ma} 002173 \mathrm{e}$ 